\title{
A cross-sectional study to estimate high-risk human papillomavirus prevalence and type distribution in Italian women aged $18-26$ years
}

Cristina Giambi ${ }^{1 *}$, Serena Donati ${ }^{1}$, Francesca Carozzi ${ }^{2}$, Stefania Salmaso ${ }^{1}$, Silvia Declich ${ }^{1}$, Marta L Ciofi degli Atti ${ }^{3}$, Guglielmo Ronco ${ }^{4}$, Maria P Alibrandi ${ }^{5}$, Silvia Brezzi ${ }^{6}$, Natalina Collina ${ }^{7}$, Daniela Franchi ${ }^{8}$, Amedeo Lattanzi ${ }^{9}$, Maria C Minna ${ }^{10}$, Roberto Nannini ${ }^{11}$, Elena Barretta ${ }^{12}$, Elena Burroni ${ }^{2}$, Anna Gillio-Tos ${ }^{13}$, Vincenzo Macallini ${ }^{14}$, Paola Pierotti ${ }^{15}$ and Antonino Bella ${ }^{1}$

\begin{abstract}
Background: Pre-vaccination information on HPV type-specific prevalence in target populations is essential for designing and monitoring immunization strategies for cervical cancer (CC) prevention. Data on HPV prevalence in Italy are available for women over the age of 24 years, target of the population-based CC screening programmes; while data of HPV prevalence in younger ages are very limited. The present study enrolled Italian women aged 1826 years in order to assess the prevalence and distribution of high-risk (HR) HPV types. Risk-factors correlated with HR-HPV positivity were also described.

Methods: A sample of 2,289 women was randomly selected from the resident population lists of ten Local Health Units (LHUs) located in six Italian Regions scattered across the country; both rural and urban LHUs were involved. Women aged between 18 and 26 years and living in the selected LHUs were included in the study; pregnant women and women who did not speak Italian were excluded. A total of 1,102 women met the inclusion criteria and agreed to participate. Participants were offered pap test and Hybrid-Capture 2 (HC2) test for HR-HPV types and genotyping was performed on positive smears.

Results: Out of 1,094 valid samples, 205 (18.7\%) were HR-HPV positive. Women with $2-4\left(\mathrm{OR}_{\mathrm{adj}}=4.15,95 \% \mathrm{Cl}\right.$ : 2.566.72) and $\geq 5$ lifetime partners $\left(\mathrm{OR}_{\mathrm{adj}}=10.63,95 \% \mathrm{Cl}\right.$ : 6.16-18.36) and women who have used any contraceptive in the last six months $\left(\mathrm{OR}_{\mathrm{adj}}=1.67,95 \% \mathrm{Cl}: 1.09-2.54\right)$ had a higher risk to be infected; women living with their partner had a lower risk $\left(\mathrm{OR}_{\mathrm{adj}}=0.56,95 \% \mathrm{Cl}\right.$ : 0.34-0.92) to acquire infection than women living with parents/friends/alone. Among HC2 positive women, HPV16 was the most prevalent type (30.9\%), followed by 31 (19.6\%), 66 (12.9\%), 51 (11.3\%), 18 (8.8\%), 56 (8.8\%). Co-infections of HR-HC2 targeted types were found in $20.4 \%$ of positive samples. The HR-HPV prevalence in women with abnormal cytology (52.4\%) was significantly higher than in women with normal cytology (14.6\%); however 33.0\% of HR-HPV infected women had an abnormal cytology.

(Continued on next page)
\end{abstract}

\footnotetext{
* Correspondence: cristina.giambi@iss.it

${ }^{1}$ Communicable Disease Epidemiology Unit, National Centre for Epidemiology, Surveillance and Health Promotion; Istituto Superiore di Sanità, Viale Regina Elena 299, 00161 Rome, Italy

Full list of author information is available at the end of the article
} 
(Continued from previous page)

Conclusion: HR-HPV prevalence in Italian women aged 18-26 years was 19\%, higher than what detected for older women, by other studies using the same molecular method and laboratory network; this result supports the choice of electing girls before the sexual debut as the primary target of HPV vaccination. The HPV type distribution found in this study may represent a baseline picture; an accurate post-vaccine surveillance is necessary to early detect a possible genotype replacement. The high prevalence of viral types other than vaccine-HPV types supports the necessity to guarantee the progression of CC screening programmes in vaccinated women.

Keywords: Human papillomavirus, High-risk types, Prevalence, Genotype distribution, Cervical cancer, Italy, Risk factors

\section{Background}

In the last decade many studies have shown that infection with high-risk (HR) types of human papillomavirus (HPV) is a necessary condition for the development of invasive cervical cancer (CC) [1]. Genital HPV infection is very common in sexually active women and is transient in most cases; only women with persistent infection by HR-HPV types are likely to develop a cervical lesion [2]. These findings led to the development of prophylactic vaccines targeted to provide protection against HPV16 and 18, responsible for the $70 \%$ of all cervical cancers; efficacy has been shown to be highest in subjects naif to the infection $[3,4]$.

As of July 2010, 18 European countries had integrated HPV vaccination in their national immunization programmes, most of them targeting pre-adolescent girls; nine countries had also planned catch up programmes for older girls [5]. In Italy HPV vaccination is included in the national immunization program and is offered to 11 year-old girls since 2007 [6]; six of the 21 Italian Regions have also extended the offer to one older birth cohort (varying by Region between 15-18 years), and one Region to three cohorts (15, 18 and 24 year-old) [7].

Pre-vaccination distribution of HPV genotypes in target populations is essential for designing, monitoring and evaluating immunization strategies. Baseline prevalence is relevant to estimate vaccine effectiveness against the HPV-vaccine types, to evaluate the cross-protection of the vaccines, and to monitor over time the relative frequency of genotypes under the selective pressure of the vaccines.

Data on HPV prevalence in Italy are available for women over the age of 24 years [8-10], target of the populationbased CC screening programmes. On the contrary there is very limited amount of data on HPV prevalence in younger ages $[11,12]$. The present study enrolled Italian women aged 18-26 years in order to assess the prevalence of HRHPV types and detect the prevalent genotypes. Risk-factors correlated with HR-HPV positivity were also described.

\section{Methods}

\section{Study design and study population}

This cross-sectional study was carried out in the period 2007-2009, coordinated by the Istituto Superiore di
Sanità (ISS, Italy's National Institute of Public Health) and partially sponsored by the Ministry of Health. It was part of a national project (PreGio), which also included a KAP (knowledge-attitudes-practices) survey on HPV infection and CC prevention [13] and a study to estimate the acceptance rate of HPV vaccination [14] .

A sample of 2,289 women was randomly selected from the resident population lists of ten Local Health Units (LHU) located in six Italian Regions scattered across the country: Abruzzo and Campania in southern Italy $(1,026)$, Lazio and Tuscany in central Italy (388) and Emilia-Romagna and Piedmont in northern Italy (875). Both rural and urban LHUs were involved; all 10 LHUs have population-based $\mathrm{CC}$ screening programmes.

The inclusion criteria for the study were: women aged between 18 and 26 years and living in the selected LHUs. Pregnant women and women who did not speak Italian were excluded. The women were stratified into two age groups (18-24 and 25-26 years), partially overlapping (25-26 years) with the target age of populationbased CC screening. Procedures for enrolling participants as well as study methodology have already been described [13,14].

All women were offered Pap-test and HPV test; a written informed consent was obtained by each participant. Selected midwives, especially trained for this study, were in charge of contacting sampled women, collecting socio-demographic data and information regarding sexual and reproductive history, getting informed consent and performing cervical smears. The study was approved by the national ethics committee of the ISS.

\section{Cytology}

Cervical smears were taken according to the consolidate CC-screening procedures at the LHU. In most Regions (Tuscany, Piedmont, Emilia-Romagna, Lazio, Campania) two cervical samples were taken: one for Pap-test and one for the HPV test in Specimen Transport Medium (STM, DNAPAP cervical sampler, Qiagen, Gaithersburg, USA); for STM sample, cytobrush was used to obtain samples. In Abruzzo Region the cervical cell specimens were put in PreservCyt solution (Hologic, Inc., Marlborough, MA) and used both for HPV testing and 
for cytological examination; for Preservcyt sample, Ayre spatula and cytobrush were used. The cytology was interpreted locally according to Bethesda 2001 system [15]. Information on reproductive, sexual and cervical screening history were collected (Table 1).
Women aged 25-26 years followed the routine protocol of treatment or follow-up according to cytological results. A specific protocol for 18-24 year-old women was adopted: colposcopy was offered to women with HSIL (high squamous intraepithelial lesions) and ASCH

Table 1 Characteristics of the study population

\begin{tabular}{|c|c|c|c|}
\hline Characteristics & & n (\%) & $\mathbf{N}$ \\
\hline \multicolumn{4}{|c|}{ Socio-demographic characteristics } \\
\hline Mean age (years) & & $23.8 \pm 0.07 *$ & 1,094 \\
\hline \multirow[t]{2}{*}{ Age group } & $18-24$ years & $598(54.7)$ & 1,094 \\
\hline & $25-26$ years & $496(45.3)$ & \\
\hline \multirow[t]{3}{*}{ Geographical area of residence } & North & $445(40.7)$ & 1,094 \\
\hline & Centre & $235(21.5)$ & \\
\hline & South & $414(37.8)$ & \\
\hline \multirow[t]{2}{*}{ Nationality } & Foreign & $69(6.3)$ & 1,092 \\
\hline & Italian & $1,023(93.7)$ & \\
\hline \multirow[t]{2}{*}{ Educational level } & Low ( $\leq 8$ years) & $216(19.8)$ & 1,090 \\
\hline & High (>8 years) & $874(80.2)$ & \\
\hline \multirow[t]{4}{*}{ Employment status } & Student & $455(42.0)$ & 1,084 \\
\hline & Employed & $415(38.3)$ & \\
\hline & Unemployed & $163(15.0)$ & \\
\hline & Housewife & $51(4.7)$ & \\
\hline \multirow[t]{3}{*}{ Marital status } & Single & $974(89.3)$ & 1,091 \\
\hline & Married & $113(10.3)$ & \\
\hline & Divorced & $4(0.4)$ & \\
\hline \multirow[t]{4}{*}{ Lives with } & parents & $813(74.7)$ & 1,089 \\
\hline & partner & $185(17.0)$ & \\
\hline & alone & $48(4.4)$ & \\
\hline & friends & $43(3.9)$ & \\
\hline \multicolumn{4}{|c|}{ Sexual behaviour and reproductive history } \\
\hline Mean age at first sexual intercourse (years) & & $17.5 \pm 0.1 *$ & 1,089 \\
\hline \multirow[t]{2}{*}{ Parity } & 0 & $988(90.4)$ & 1,093 \\
\hline & $\geq 1$ child & $105(9.6)$ & \\
\hline Mean age at first delivery (years) & & $21.7 \pm 0.3 *$ & 105 \\
\hline \multirow[t]{3}{*}{ No. of lifetime partners } & 1 & $377(34.6)$ & 1,091 \\
\hline & $2-4$ & $558(51.1)$ & \\
\hline & $\geq 5$ & $156(14.3)$ & \\
\hline \multirow[t]{4}{*}{ No. of partners in the last 6 months } & 0 & $69(6.3)$ & 1,093 \\
\hline & 1 & $962(88.0)$ & \\
\hline & $2-4$ & $53(4.9)$ & \\
\hline & $\geq 5$ & $9(0.8)$ & \\
\hline \multirow[t]{2}{*}{ Use of contraceptives in the last 6 months } & Yes & $762(74.5)$ & 1,023 \\
\hline & $\overline{\mathrm{No}}$ & $261(25.5)$ & \\
\hline \multirow[t]{3}{*}{ Use of condoms in the last 6 months } & Always & $346(33.9)$ & 1,020 \\
\hline & Rarely & $307(30.1)$ & \\
\hline & Never & $369(36.0)$ & \\
\hline \multirow[t]{2}{*}{ Previous Pap-test } & Yes & $420(38.5)$ & 1,091 \\
\hline & No & $671(61.5)$ & \\
\hline
\end{tabular}

* (mean \pm Standard Error). 
(atypical squamous cells that cannot exclude high-grade lesions), while women with LSIL (low squamous intraepithelial lesions) or less severe lesions were invited to repeat pap-test two years later and colposcopy was offered only if, after two years, the diagnosis was still LSIL or it progressed to a more severe lesion.

\section{HPV testing}

The HPV test was performed using Hybrid Capture 2 (HC2 High-Risk HPV DNA, Qiagen; Hilden, Germany) according to the manufacturer's instructions. It is a hybridization assay which detects the presence of HPVDNA using cocktails of RNA probes and an amplified, chemiluminescent signal. The high-risk group of probes $\mathrm{B}$, designed to detect HPV types $16,18,31,33,35,39$, $45,51,52,56,58,59$ and 68 , was used. The assay is calibrated on a positive cut off (pc) of $1 \mathrm{pg} / \mathrm{ml}$ of HPVDNA. Samples were considered positive when the ratio between the Relative Light Units (RLU) of specimen and the pc attained or exceeded the value of 1.0.

A regional laboratory was identified in Tuscany, Piedmont, Abruzzo and Emilia-Romagna Regions for performing HPV testing; the Analytical and Biomolecular Cytology Unit of the Cancer Prevention and Research Institute (ISPO) in Tuscany also analysed samples from Campania and Lazio Regions.

\section{Genotyping}

Genotyping was performed on HR-HC2 positive samples. DNA was extracted using the QIAamp DNAMini kit (Qiagen) according to the manufacturer's instructions. For PreservCyt ${ }^{\mathrm{Tm}}$ samples the elution volume varied from 80 to $100 \mu \mathrm{l}$ depending on the size of the pellet, while for STM samples $100 \mu$ l of elution buffer (Buffer AE) were used. To facilitate a higher recovery of DNA a double elution was done for all the samples. HR-HC2 positive samples were typed using the "Consensus High Risk HPV genotyping" kit assay (Digene Corporation, Gaithersburg, USA). The test is based on the reverse hybridization principle. Denaturated biotynilated amplicons, resulting from the amplification of a part of the L1 region with GP5+/GP6+ primers, were hybridized with specific oligonucleotide probes, which were immobilized as parallel lines on membrane strips (Reverse Line Blot Hybridization). The hybrids were detected with alkaline phosphatase-streptavidin conjugate and substrate (5bromo-4-chloro-3-indolylphosphate and nitroblue tetrazolium), resulting in a purple precipitate at positive probe lines. The kit allows the identification of $18 \mathrm{HPV}$ types $(16,18,26,31,33,35,39,45,51,52,53,56,58,59$, $66,68,73,82)$. One HPV-positive control and two negative PCR controls (a purified DNA sample negative for HPV and a DNA free sample) were included in each PCR run and subsequent Reverse Line Blot (RLB).
GP5+/GP6+ PCR-negative and RLB-negative samples were amplified for the $\beta$-globin gene sequence using GH20-PC04 primers (268-bp amplicon length) to assess DNA integrity (Bauer).

The molecular Laboratory of ISPO performed genotyping of samples collected in all Italian regions involved in the study except samples collected in Piedmont Region, which were genotyped at the Center for Experimental Research and Medical Science of the Turin University. ISPO also coordinated the molecular activities of the whole project, standardizing the procedures for storing and analysing the samples according to a protocol defined to guarantee the quality of molecular methods [16].

\section{Statistical analysis}

Categorical variables were summarized by absolute frequencies and percentages, and continuous variables by means and Standard Error (SE). The Chi-square test and Fisher's exact test were used to compare proportions; the $t$-test or Mann-Whitney nonparametric test was used to compare continuous variables. Crude and adjusted odds ratios (OR) and 95\% confidence intervals (95\%CI) were calculated to evaluate the association between the HR-HPV positivity and socio-behavioural characteristics.

Confounding was assessed by a multivariate logistic regression approach; all variables with a p-value $\leq 0.15$ in the univariate analysis were included in the multivariate model and retained in the final model according to a log-likelihood-ratio test for goodness-of-fit. Statistical analysis was performed using STATA 11.2 (Stata Corporation, College Station, Texas, USA).

\section{Results}

\section{Study population}

Recruitment was performed in the period ranging from February 2008 to April 2009. The initial sample included 2,289 women; 239 did not meet the inclusion criteria (124 did not live in the selected LHU, 57 were pregnant, 45 were not included in the 18-26 years range of age and 13 did not speak Italian) and were replaced, and 290 could not be contacted. Thus 1,999 women were offered Pap test and HPV test. Among them, 897 (44.9\%) declined participation for several issues (non interested in the study, practical constraints, health disorders, HPV-positivity, recent previous Pap-test, embarrassment, parental advice, safety concerns, no sexual activity) (Figure 1). Women who did not participate were slightly younger than participants (mean age $23.2 \pm 0.09$ vs. $23.9 \pm 0.07$ years; $\mathrm{p}<0.001$ ); the proportion of women with a lower education level $(24.6 \%$ vs $19.9 \%$; $\mathrm{p}=0.017)$, living with parents (87.9 vs $74.6 \%$; $\mathrm{p}=0<001)$, unmarried (93.5 vs $89.5 \% ; \mathrm{p}=0.003$ ) and living in southern 


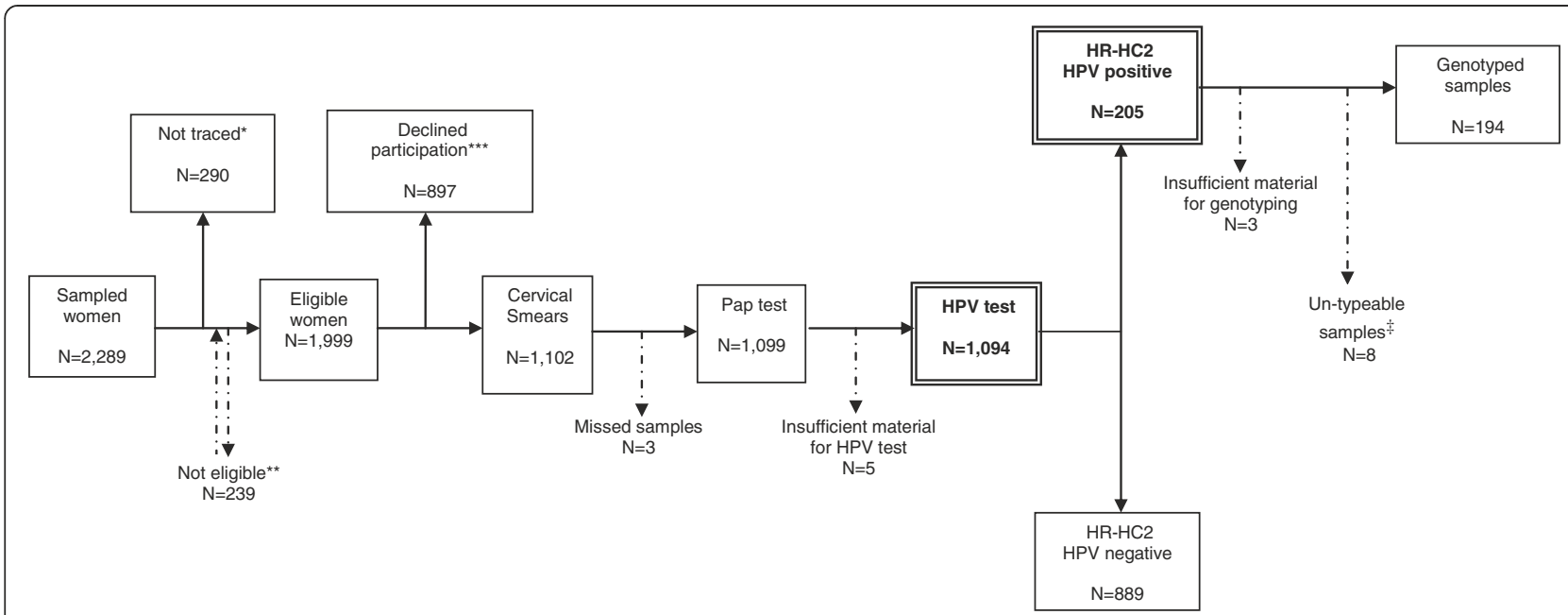

Figure 1 Study population. *Not traced: women who were not traced although three phone calls and two home visits. ${ }^{* *}$ Not eligible: women who did not meet inclusion criteria and were replaced with women of the same age group and local health unit. ${ }^{* * *}$ Declined participation: women who were contacted and met the inclusion criteria, but refused to participate in the prevalence study. ${ }^{*}$ Un-typeable samples: HR-HC2 positive samples that resulted negative at any of the 18 types identifiable by the kit assay used for genotyping.

Italy $(53.3 \%$ vs $38.0 \%$; $<0.001)$ was higher in the group of women who refused to participate.

In conclusion a total of 1,102 out of 2,289 women (48.1\%) were enrolled in the study. In order to calculate the participation rate to the prevalence study, we considered more appropriate to exclude from the denominator $(2,289)$ the 154 women (among the 897 women who declined participation) who spontaneously declared not to be sexually active: therefore the participation rate was $51.6 \%(1,102 / 2,135)$, with a range among LHUs of 23.980.7 .

The mean age of participants was $23.8 \pm 0.07$ years; $40.7 \%$ lived in northern Italy, $37.8 \%$ in southern Italy, and $21.5 \%$ in central Italy. Most women were Italian (93.7\%), unmarried (89.3\%) and had a high educational level, defined as $>8$ years of education (80.2\%). Detailed socio-behavioural characteristics are shown in Table 1.

\section{HPV prevalence and genotyping}

The Pap-test was performed on 1,099 cervical smears because three samples were missed (they were included in the CC screening programme, instead of being included in the PreGio study) and the HR-HPV testing was performed on 1,094 out of 1,999 samples (the material of five samples was not sufficient for HR-HC2 test). The proportion of HR-HC2 positive samples was $18.7 \%(205 / 1,094)$ and did not differ by geographic area and age group (Table 2).

The genotyping was performed on 202/205 HR-HPV positive samples (three samples were not adequate because material was not sufficient for genotyping) and 194 (96\%) showed positivity at least for one of the 18 types identifiable by the kit assay used for genotyping. In contrast, eight samples (4\%) did not result positive at any of these 18 types: this proportion is in line with data reported in literature $[17,18]$ and is mainly due to the cross-reactivity of the probe B with low-risk HPV types.

Among Hybrid Capture positive women HPV16 was the most prevalent type (30.9\%), followed by 31 (19.6\%), 66 (12.9\%), 51 (11.3\%), 18 (8.8\%), 56 (8.8\%) and 58 (8.3\%); all the other types were detected at frequencies lower than $5.2 \%$ (Table 3); the cumulative rate of 16 and 18 was $38.7 \%$.

The prevalence of HPV 26, 53, 66, 73, 82 is underestimated because these HPV types are detected by the "Consensus High Risk HPV genotyping" assay, but they are not targeted by HR-HC2 test; the detection of HPV $26,53,66,73,82$ is due to an occasional crosshybridization of HR-HC2 method or co-infection with HPV-targeted types, therefore they could more likely appear in multiple than single infections. For this reason we limited the analysis of multiple infections to the 13 HR-HPV types targeted by HR-HC2 test.

Out of 181 women infected by HR-HC2 targeted types, $37(20.4 \%)$ had a multiple infection (36 infected by two types and one by three types). No difference in socio-demographic characteristics and sexual and reproductive history was found between women presenting a multiple and single infection. HPV16 was the most common genotype detected in multiple infections, followed by HPV31 and 18. Table 4 shows the distribution of HPV types in single and multiple infections; the proportion of single and co-infections by genotype is also reported: the proportion of infections occurring in conjunction with other types did not significantly differ by HPV type (Fisher's exact test: $\mathrm{p}=0.264$ ). 
Table 2 Determinants of HR-HPV prevalence: univariate (OR crude) and multivariate (OR adj) logistic regression analysis

\begin{tabular}{|c|c|c|c|c|c|c|}
\hline \multirow[t]{2}{*}{ Characteristics } & & \multirow{2}{*}{$\begin{array}{l}\text { HR-HPV positivity } \\
\text { n/N (\%) }\end{array}$} & \multicolumn{2}{|c|}{ Univariate analysis } & \multicolumn{2}{|c|}{ Multivariate model $^{* *}$} \\
\hline & & & OR crude & $95 \% \mathrm{Cl}$ & OR adj & $95 \% \mathrm{Cl}$ \\
\hline \multirow[t]{2}{*}{ Age Group } & $18-24$ years & 119/597 (19.9) & 1 & - & & \\
\hline & $25-26$ years & $86 / 496(17.3)$ & 0.84 & $(0.62-1.14)$ & & \\
\hline \multirow[t]{3}{*}{ Geographical area of residence } & Centre & $44 / 235(18.8)$ & 1 & - & & \\
\hline & North & $86 / 445(19.3)$ & 1.03 & $(0.69-1.55)$ & & \\
\hline & South & $75 / 414(18.1)$ & 0.95 & $(0.63-1.44)$ & & \\
\hline \multirow[t]{2}{*}{ Nationality } & Foreign & 13/69 (18.8) & 1 & - & & \\
\hline & Italian & 192/1023 (18.7) & 0.99 & $(0.53-1.86)$ & & \\
\hline \multirow[t]{2}{*}{ Educational level } & Low ( $\leq 8$ years) & $39 / 216(18.1)$ & 1 & - & & \\
\hline & High (>8 years) & 166/874 (19.0) & 1.06 & $(0.72-1.56)$ & & \\
\hline \multirow[t]{3}{*}{ Employment status } & Student & 79/455 (17.4) & 1 & - & & \\
\hline & Employed & $80 / 415$ (19.3) & 1.14 & $(0.80-1.60)$ & & \\
\hline & Other & $45 / 214(21.0)$ & 1.27 & $(0.84-1.91)$ & & \\
\hline \multirow[t]{2}{*}{ Marital status } & Single & 197/974 (20.2) & 1 & - & & \\
\hline & Married & $8 / 113(7.1)$ & 0.30 & $(0.14-0.63)$ & & \\
\hline \multirow[t]{2}{*}{ Lives with } & Parents/friends/alone & 182/904 (20.1) & 1 & - & 1 & - \\
\hline & Partner & 22/185 (11.9) & 0.53 & $(0.33-0.86)$ & 0.56 & $(0.34-0.92)$ \\
\hline Mean age at first sexual intercourse (years) & & $* 17.2$ & 0.92 & $(0.85-0.99)$ & & \\
\hline \multirow[t]{2}{*}{ Parity } & 0 & 195/988 (19.7) & 1 & - & & \\
\hline & $\geq 1$ child & 10/105 (9.5) & 0.43 & $(0.22-0.84)$ & & \\
\hline Mean age at first delivery (years) & & $* 21.8$ & 1.01 & $(0.78-1.30)$ & & \\
\hline \multirow[t]{3}{*}{ No. of lifetime partners } & 1 & $25 / 377(6.3)$ & 1 & - & 1 & - \\
\hline & $2-4$ & $118 / 558(21.1)$ & 3.78 & $(2.40-5.94)$ & 4.15 & $(2.56-6.72)$ \\
\hline & $\geq 5$ & $62 / 156(39.7)$ & 9.29 & $(5.54-15.57)$ & 10.63 & $(6.16-18.36)$ \\
\hline \multirow[t]{2}{*}{ No. of partners in the last 6 months } & $0-1$ & 181/1031 (17.6) & 1 & - & & \\
\hline & $\geq 2$ & 24/62 (38.7) & 2.96 & $(1.73-5.07)$ & & \\
\hline \multirow[t]{2}{*}{ Use of contraceptives in the last 6 months } & No & $35 / 261(13.4)$ & 1 & - & 1 & - \\
\hline & Yes & $159 / 762(20.9)$ & 1.70 & $(1.14-2.53)$ & 1.67 & $(1.09-2.54)$ \\
\hline \multirow[t]{3}{*}{ Use of condoms in the last 6 months } & Always & $68 / 346(19.7)$ & 1 & - & & \\
\hline & Rarely & $65 / 307(21.2)$ & 1.10 & $(0.75-1.60)$ & & \\
\hline & Never & $61 / 367(16.6)$ & 0.81 & $(0.56-1.19)$ & & \\
\hline \multirow[t]{2}{*}{ Previous Pap-test } & No & 135/671 (20.1) & 1 & - & & \\
\hline & $\overline{\text { Yes }}$ & $70 / 420(16.7)$ & 0.79 & $(0.58-1.09)$ & & \\
\hline
\end{tabular}

*mean.

**The following variables have been included in the multivariate model: marital status, living with, mean age at first sexual intercourse, mean age at first delivery, parity, number of lifetime partners, number of partners in the last 6 months, use of contraceptives in the last 6 months.

\section{Determinants of high risk HPV prevalence}

The univariate analysis of socio-behavioural characteristics and HR-HPV infection is reported in Table 2. The risk of HR-HPV infection resulted significantly higher in women who declared a greater number of partners in lifetime $(\mathrm{OR}=3.78,95 \% \mathrm{CI}: 2.40-5.94$ if $2-4$ partners and $\mathrm{OR}=$ 9.29, 95\% CI: $5.54-15.57$ if $\geq 5$ partners) and in the last six months $(\mathrm{OR}=2.96,95 \% \mathrm{CI} 1.73-5.07$ if $\geq 2$ partners $)$, and in women who have used any contraceptive method in the last six months $(\mathrm{OR}=1.70,95 \% \mathrm{CI} 1.14-2.53)$. In contrast, the risk of HR-HPV infection resulted significantly lower in women living with their partner compared to women living with parents/friends/alone $(\mathrm{OR}=0.53$, 95\%CI: 0.33$0.86)$, in married women $(\mathrm{OR}=0.30,95 \% \mathrm{CI}$ : $0.14-0.63)$ and women with children ( $\mathrm{OR}=0.43,95 \% \mathrm{CI}$ : $0.22-0.84)$. Also a higher age at the first intercourse showed a protective effect $(\mathrm{OR}=0.92$, 95\%CI: 0.85-0.99).

The following variables were included in the multivariate model: marital status, "living with", age at first sexual intercourse, age at first delivery, parity, number of lifetime partners, number of partners in the last six months, use of contraceptives in the last six months. 
Table 3 Distribution of HPV genotypes in HR-HC2 test positive women and overall population

\begin{tabular}{|c|c|c|c|}
\hline $\begin{array}{c}\text { HPV } \\
\text { genotypes }\end{array}$ & $\begin{array}{l}\text { Number of } \\
\text { infections }\end{array}$ & $\begin{array}{l}\text { HR-HC2 test } \\
\text { positive women } \\
(\mathrm{N}=194), \%\end{array}$ & $\begin{array}{c}\text { Overall } \\
\text { population* } \\
\text { (N=1094), \% }\end{array}$ \\
\hline 16 & 60 & 30.9 & 5.5 \\
\hline 31 & 38 & 19.6 & 3.5 \\
\hline $66^{* *}$ & 25 & 12.9 & 2.3 \\
\hline 51 & 22 & 11.3 & 2.0 \\
\hline 18 & 17 & 8.8 & 1.6 \\
\hline 56 & 17 & 8.8 & 1.6 \\
\hline 58 & 16 & 8.3 & 1.5 \\
\hline 59 & 10 & 5.2 & 0.9 \\
\hline 52 & 9 & 4.6 & 0.8 \\
\hline 39 & 9 & 4.6 & 0.8 \\
\hline 45 & 8 & 4.1 & 0.7 \\
\hline $53^{* *}$ & 7 & 3.6 & 0.6 \\
\hline 33 & 6 & 3.1 & 0.5 \\
\hline 68 & 6 & 3.1 & 0.5 \\
\hline $73^{* *}$ & 3 & 1.5 & 0.3 \\
\hline 35 & 2 & 1.0 & 0.2 \\
\hline $82^{* *}$ & 1 & 0.5 & 0.1 \\
\hline $26^{* *}$ & 0 & 0.0 & 0.0 \\
\hline
\end{tabular}

* HPV type-specific prevalence has been extrapolated to overall population although it should be stressed that the genotyping was performed only on HR-HC2 positive samples.

** The prevalence of HPV $26,53,66,73,82$ is probably underestimated because these HPV types are detected by the "Consensus High Risk HPV genotyping" assay, but they are not targeted by the HR-HC2 test.

In the multivariate logistic regression model (Table 2), the effect of the number of lifetime sexual partner remained statistically significant $\left(\mathrm{OR}_{\mathrm{adj}}=4.15,95 \% \mathrm{CI}\right.$ : 2.56-6.72 if 2-4 partners and $\mathrm{OR}_{\mathrm{adj}}=10.63$, 95\%CI: 6.1618.36 if $\geq 5$ partners). Also, living with the sexual partner and having used any contraceptive in the last six months remained significantly associated with the detection of HR-HPV infection $\left(\mathrm{OR}_{\mathrm{adj}}=0.56,95 \% \mathrm{CI}: 0.34-0.92\right.$ and $\mathrm{OR}_{\mathrm{adj}}=1.67,95 \% \mathrm{CI}: 1.09-2.54$ respectively).

\section{Cytology}

The pap-test result was available for 1,093/1,094 cervical smears tested for HR-HC2; 5.7\% $(62 / 1,093)$ of samples were inadequate, cytology was normal in $83.0 \%$ samples (907/1,093) and abnormal in $11.3 \%(124 / 1,093)$ samples: 62 ASCUS/AGUS (atypical squamous/glandular cervical cells of undetermined significance), 52 LSIL, 6 ASCH and 4 HSIL. The proportion of HR-HPV positivity was significantly higher in women with abnormal cytology $(65 / 124,52.4 \%)$ than in women with normal cytology $(132 / 907,14.6 \%)(\mathrm{p}<0,001)$. Among the $197 \mathrm{HPV}$ infected women with adequate cytology, 65 (33.0\%) had an abnormal finding.
Table 4 Distribution of HPV genotypes in single/multiple infections and proportion of single/multiple infections by type

\begin{tabular}{|c|c|c|c|c|}
\hline \multirow{2}{*}{$\begin{array}{c}\text { HPV } \\
\text { genotypes* }\end{array}$} & \multicolumn{2}{|c|}{ Single infections } & \multicolumn{2}{|c|}{ Multiple infections } \\
\hline & $\mathrm{n}$ & $\%^{* *}$ & $\mathrm{n}$ & $\% * *$ \\
\hline 16 & 43 & 71.7 & 17 & 28.3 \\
\hline 31 & 21 & 55.3 & 17 & 44.7 \\
\hline 51 & 16 & 72.7 & 6 & 27.3 \\
\hline 18 & 7 & 41.2 & 10 & 58.8 \\
\hline 56 & 12 & 70.6 & 5 & 29.4 \\
\hline 58 & 11 & 68.7 & 5 & 31.3 \\
\hline 59 & 6 & 60.0 & 4 & 40.0 \\
\hline 52 & 5 & 55.6 & 4 & 44.4 \\
\hline 39 & 6 & 66.7 & 3 & 33.3 \\
\hline 45 & 7 & 87.5 & 1 & 12.5 \\
\hline 33 & 3 & 50.0 & 3 & 50.0 \\
\hline 68 & 6 & 100.0 & 0 & 0.0 \\
\hline 35 & 1 & 50.0 & 1 & 50.0 \\
\hline All & 144 & 65.5 & 76 & 34.5 \\
\hline
\end{tabular}

* All genotypes from single and multiple infections were computed individually.

** The denominator is represented by the total number of infections (single plus multiple) by genotype.

HPV16 was the most frequent virus strain in normal cytology, ASCUS/AGUS, LSIL and ASCH, detected in $29.3,47.8,24.2$ and $66.7 \%$ of the samples respectively. All the four HSIL were HR-HPV positive and four different types were detected respectively $(16,18,31,33)$.

\section{Discussion}

We found a prevalence of HR-HPV infections of $19 \%$ in a sample of Italian women aged 18-26 years. This percentage is in agreement with an Italian study which used a similar methodology to measure the HR-HPV prevalence in 18-24 year-old women from Tuscany Region [11]. This value is also included within the range (20$45 \%)$ reported in other national or worldwide studies for women younger than 25 years [12,19-22], although it is difficult to compare results of different studies because of different age groups and different procedures for enrolling participants. Not surprisingly, the rate of infection in this age group was higher than what was found in women aged 25-29 (14\%) in New Technologies for CC screening (NTCC) randomized trials, which studied 45,000 women aged 25-60 years of northern and central Italy, participating in CC screening programmes $[8,9]$. This finding reflects a higher probability of acquiring new infections at younger ages, confirming the trend described in the international literature with a peak of HR-HPV prevalence in younger women and a continuous decline with increasing age [19-22]. 
Cervical cancer incidence is lower in the South than in the North of Italy, therefore a lower HR-HPV prevalence in the general population was expected in the South. Instead, we did not find any difference in HR-HPV prevalence rates between northern, central and southern regions of Italy, confirming what reported by Agarossi and coll. [22]. This finding should encourage the implementation, strengthening and promotion of cervical cancer screening programmes in southern Italy, where coverage and acceptance are still lower than in the rest of the country [23].

Genotype HPV16 was detected in 31\% of HR-HC2 positive samples, followed by $31,66,51$ and 18 . This is well consistent with the results of a comprehensive meta-analysis on HPV positive women with normal cytology conducted by de Sanjosé and coll. [24], which reported HPV16, 31 and 18 among the five most common types worldwide. In Italy, HPV16 resulted to be the genotype most frequently detected in all studies and HPV 31 was frequently reported as the second most common genotype $[11,22,25,26]$. Regarding the other genotypes a high variability is reported among studies, which could be due to geographical differences, different target populations, different methods for genotyping and random fluctuation for quite rare genotypes $[27,28]$.

According to the International Agency for Research on Cancer (IARC) classification, HPV16, 31, 51 and 18 are classified as "carcinogenic to humans", while HPV 66 is classified as "possibly carcinogenic" [29]. It should be also mentioned that the prevalence of HPV 66, as of the other genotypes not targeted by HR-HC2 (HPV 53, $26,73,82$ ), observed in the present study is plausibly underestimated because the detection of these types is only due to an occasional cross-hybridization of the method or co-infection with HPV-targeted types.

As expected, we found that women with cervical cytological abnormalities were at significantly increased risk for being infected by HR-HPV types than women with normal cytology (52 vs. 15\%). Current Italian studies involving women with cytological abnormalities (different ages and enrolment criteria) reported HR-HPV prevalence of $34-68 \%$, increasing with cytology severity: $24-56 \%$ in case of diagnosis of ASCUS/AGUS, 42-72\% in LSIL and 73-95\% in HSIL [21,22,26,27,30-32].

Co-infections of HR-HC2 targeted types represented the $20 \%$ of HPV positive samples. This value is included in the range (15-50\%) reported in literature [33]; similar percentages of single and multiple HPV infections have been observed in young general populations [34,35]. It is still not clear whether co-infection with multiple types increases the risk of progression to cancer $[22,36]$.

The multivariate analysis evidenced the role of the number of lifetime sexual partners as determinant of HPV infection, consistently with other studies [11,12,21,37], and strengthens the concept that that the most suitable age for HPV vaccination is the period preceding sexual activity. Living with partner had a protective effect against HR-HPV infection in the multivariate model; consistently with another Italian study [38], being married and having children showed a protective effect in the crude analysis, although not statistically significant in the multivariate analysis. All these variables could be considered markers of a steady relationship, explaining the association with a low HR-HPV prevalence. The use of any contraceptive method in the last six months remained associated to HRHPV infection in the final model; we could suppose that women who used contraceptives in the last six months could have had a more intense sexual activity, with a higher risk of acquiring HPV, whose prevalence is higher in young ages. If considering only the use of condoms in the last six months, no association was detected between HR-HPV prevalence and this method of contraception; this point is debated and conclusions about the association between condoms' use and HR-HPV prevalence are discordant among authors [11].

The major strengths of this study are that the sample was large and it targeted an age group that has not been investigated extensively.

Among the limitations, it should be mentioned the fact that our sample may not be entirely representative of Italy's general population of females aged 18-26 years because only ten LHUs in six Regions participated, though local probabilistic samples were populationbased and both urban and rural LHUs in northern, central and southern Italy were involved.

In addition the participation rate was $52 \%$, therefore our findings could not be representative of the entire study population; however differences in socio-demographic characteristics between participants and people who declined participation were minimal.

The participation rate could be underestimated because we have excluded from the initial sample the 154 women who spontaneously declared not to be sexually active, but we do not know if other women, who declined participation, were virgin too (we did not collect this information). This age group represents a difficult target for prevention measures, because in Italy young adult women are not accustomed to being targeted by preventive programmes; moreover, enrolled women were offered the participation to a package of activities within the PreGio project, which is more difficult to be accepted than a single cervical smear. On the other hand, it should be noted that the study personnel had received special training and that a high number of attempts were made to contact non-respondents. Two other studies $[11,12]$, which detected HPV prevalence of a sample of Italian women aged 18-24 years randomly selected from population registries, got a lower participation rate 
(15-22\%). In these two studies letters of invitation were mailed to sampled women and a reminder was sent in case of no response, whereas we planned three phone calls and two home visits for non respondents.

As already mentioned, another limitation is that the prevalence of HPV 26, 53, 66, 73 and 82 could be heavily underestimated because they are not targeted by HRHC2 test. In fact HPV 73 and 82 were observed only in co-infection with other HR-HPV types, suggesting that they could have been found only because coexisted with HPV types detected by HR-HC2 probes B (for this reason we excluded $\mathrm{HR}-\mathrm{HC} 2$ not targeted types from the analysis of co-infections).

\section{Conclusion}

We measured the genital HR-HPV prevalence in Italian women aged 18-26 years before the introduction of $\mathrm{HPV}$ vaccination across all the areas of Italy; we found a prevalence of $19 \%$, higher than what detected for older women [19-22]. The use of the same molecular method and laboratory network of the NTCC studies [8,9], targeting women aged 25-60 years, allowed us to depict a comprehensive picture of HR-HPV prevalence in Italy from 18 to 60 years of age, observing in young adult women a peak of prevalence, which drops with increasing age. The findings support the choice of electing girls before the sexual debut as the primary target of HPV vaccination.

The HPV type distribution found in this study may represent a baseline picture; an accurate post-vaccine surveillance is, in fact, necessary to early detect a possible genotype replacement. The high prevalence of viral types other than vaccine-HPV types supports the necessity to guarantee the progression of CC screening programmes in vaccinated women. Studies linking screening programmes with vaccine immunization registries should be performed to evaluate the HPV vaccine effectiveness on vaccinerelated and not-vaccine related types.

\section{Competing interests}

The authors declare that they have no competing interests.

\footnotetext{
Authors' contributions

CG coordinated and monitored the project activities, analysed the data, interpreted the results, drafted and edited the manuscript. SDo designed the study, coordinated and monitored the project activities, interpreted the results and revised the manuscript. FC and GR participated in the study design, carried out the immunoassays, coordinated the activities of laboratories and revised the manuscript. SS designed the study, interpreted the results and revised the manuscript. SDe coordinated and monitored the project activities and revised the manuscript. MLCdA designed the study, coordinated and monitored the project activities in the first phase of the project and revised the manuscript. $A B$ analysed the data and revised the manuscript. MPA, SB, NC, DF, AL, MCM, RN, EB participated in the study design and coordinated the activities in their local health units. $E B, A G, V M$, PP carried out the immunoassays. All authors read and approved the final manuscript.
}

\section{Acknowledgments}

We wish to thank all the additional members of the PreGio Working group ${ }^{1}$ for their precious and active collaboration in all the activities of this study. We also wish to thank all the enrolled women, whose participation was essential to achieve the PreGio results.

${ }^{1}$ Additional members of the PreGio Working Group: B. De Mei, S. De Santis, A. Filia, S. Giannitelli, S. Lana, F. Meduri, G. Nacca, A. Ranghiasci (ISS, Roma); M. Toschi (Umbria Region); L. Caroselli, M. Gallese, C. Gallina, R. Nardella (Avezzano/Sulmona LHU); C. Angeloni, S. Acciavatti, A. Angelozzi, M. Di Febo, R. Mucciarelli (Teramo LHU); C. Granchelli, M. Patrizii, I. Taglione, E. Tini (Pescara LHU); MT. Pini, M. Faredo, G. Gallicchio, R. Granata, A. Improta, E. Lorido, A. Musella, MA. Petricciuoli, I. Scherillo (Napoli 2 Nord LHU); M. Becca, P. Cavalli, P. Quercia, R. Raspanti, O. Turrini (Imola LHU); MG. Aloi, G. Belletti, P. Biavati, A. Calzolari, B. Fava, A. Montrone, G. Nanetti, D. Onofri, S. Salerno (Bologna LHU); L. Bonelli, A. Brachini, T. Cappelli, AM. Casciani, G. Esposito, M. Mosconi, P. Polesi (Viterbo LHU); E. Anselmo, L. Avalle, P. Baracco, E. Lucchini (Ivrea 9 LHU); M. Meda, G. Cavani (Torino 1 LHU); M. Caruana, R. Rizzolo (CPO, Torino); MG. Santini, S. Peroni, S. Pini, D. Trotto (AS Firenze); L. Brandigi, C. Di Pierro, C. Sani (ISPO Firenze); L. De Marco (CERMS, University of Turin).

\section{Author details}

${ }^{1}$ Communicable Disease Epidemiology Unit, National Centre for Epidemiology, Surveillance and Health Promotion; Istituto Superiore di Sanità, Viale Regina Elena 299, 00161 Rome, Italy. ${ }^{2}$ Analytical Cytology and Biomolecular Unit, Cancer Research and Prevention Institute, Via Cosimo il Vecchio 2, 50139 Florence, Italy. ${ }^{3}$ Medical Direction, Bambino Gesù Children's Hospital, Piazza S. Onofrio 4, 00165 Rome, Italy. ${ }^{4}$ Unit of cancer epidemiology, Center for Cancer Prevention, S. Francesco da Paola 31, 10123 Turin, Italy. ${ }^{5}$ Hygiene and Public Health Unit, LHU Torino4, Via Aldisio 2, Ivrea, 10015 Turin, Italy. ${ }^{6}$ Department of Prevention, LHU Viterbo, via Enrico Fermi 15, 01100 Viterbo, Italy. ${ }^{7}$ Public Health Department, LHU Bologna, Via del Seminario 1, San Lazzaro di Savena, 40068, Bologna, Italy. ${ }^{8}$ Department of Prevention, LHU Avezzano-Sulmona-L'Aquila, Via Monte Velino 18, 67051 Avezzano, L'Aquila, Italy. ${ }^{~} S a n$ Liberatore Hospital, LHU Teramo, Viale Risorgimento, 64032 Atri, Teramo, Italy. ${ }^{10}$ Community Medicine Unit, LHU Pescara, Via Paolini 45, 65124 Pescara, Italy. ${ }^{11}$ Oncologic Screening Center, LHU Imola, viale Amendola 8, 40026 Imola, Bologna, Italy. ${ }^{12}$ Mother and Child Department, LHU Napoli 2 Nord, Corso Italia 129, 80010 Quarto, Napoli, Italy. ${ }^{13}$ Center for Experimental Research and Medical Science, University of Turin, Via Santena 7, 10126 Turin, Italy. ${ }^{14}$ S. Rinaldi Hospital, Via Serafino Rinaldi 63, 67057 Pescina, L'Aquila, Italy. ${ }^{15}$ Maggiore Hospital, LHU Bologna, Largo B. Nigrisoli 2, 40133 Bologna, Italy.

Received: 20 September 2012 Accepted: 29 January 2013 Published: 7 February 2013

\section{References}

1. Bosch FX, Lorincz A, Muñoz N, Meijer CJLM, Shah KV: The causal relation between human papillomavirus and cervical cancer. J Clin Pathol 2002, 55:244-265.

2. Baseman JG, Koutsky LA: The epidemiology of human papillomavirus infections. J Clin Virol 2005, 32S:S16-S24.

3. World Health Organization position paper: Human papillomavirus vaccines. Weekly epidemiological record 2009, 15(84):117-132. Available at: http://www.who.int/wer/2009/wer8415.pdf. Accessed 4 May 2012.

4. Mariani L, Monfulleda N, Alemany L, Vizza E, Marandino F, Vocaturo A, et al: Human Papilloma Virus prevalence and type-specific relative contribution in invasive cervical cancer specimens from Italy. BMC Cancer 2010, 10:259.

5. Dorleans F, Giambi C, Dematte L, Cotter S, Stefanoff P, Mereckiene J, et al: The current state of introduction of human papillomavirus vaccination into national immunisation schedules in Europe: first results of the VENICE2 2010 survey? Euro Surveill 2010, 15(47). Available at: http://www. eurosurveillance.org/ViewArticle.aspx?Articleld=19730. Accessed 4 May 2012.

6. Presidency of the Council: State-Regions Agreement "Strategies for HPV Vaccination Active Offer in Italy". Italian: 2007. Available at: http://www. statoregioni.it/Documenti/DOC_016696_264\%20csr.pdf. Accessed 4 May 2012.

7. Giambi C: Progresses of HPV Vaccination Campaign: Vaccination Coverage Data at 31/12/2011. Available at: http://www.epicentro.iss.it/problemi/hpv/ pdf/Aggiornamento_datiHPV_31_12_2011_validato.pdf. Accessed 18 May 2012. 
8. Ronco G, Brezzi S, Carozzi F, Dalla Palma P, Giorgi-Rossi P, Minucci D, et al: NTCC study group. The New technologies for cervical cancer screening randomized controlled trial. An overview of results during the first phase of recruitment. Gynecol Oncol 2007, 107:S230-S232.

9. Ronco G, Giorgi-Rossi P, Carozzi F, Confortini M, Dalla Palma P, Del Mistro A, NTCC Working Group, et al: Efficacy of human papillomavirus testing for the detection of invasive cervical cancers and cervical intraepithelial neoplasia: a randomized controlled trial. Lancet Oncol 2010, 11:249-257.

10. Giorgi-Rossi P, Bisanzi S, Paganini I, Di lasi A, Angeloni C, Scalisi A, HPV Prevalence Italian Working Group, et al: Prevalence of HPV high and low risk types in cervical samples from the Italian general population: a population based study. BMC Infect Dis 2010, 10:214.

11. Confortini M, Carozzi F, Zappa M, Ventura L, lossa A, Cariaggi P, et al: Human papillomavirus infection and risk factors in a cohort of Tuscan women aged 18-24: results at recruitment. BMC Infect Dis 2010, 10:157.

12. Ammatuna P, Giovannelli L, Matranga D, Ciriminna S, Perino A: Prevalence of genital human papilloma virus infection and genotypes among young women in Sicily, South Italy. Cancer Epidemiol Biomarkers Prev 2008, 17:2002-2006.

13. Donati A, Giambi S, Declich S, Salmaso S, Filia A, Atti ML Cd, The PreGio Working group, et al: Knowledge, attitude and practice in primary and secondary cervical cancer prevention among young adult Italian women. Vaccine 2012, 30:2075-2082.

14. Giambi C, Donati S, Declich S, Salmaso S, Atti ML Cd, Alibrandi MP, The PreGio Working Group, et al: Estimated acceptance of HPV vaccination among Italian women aged 18-26 years. Vaccine 2011, 29:8373-8380.

15. Solomon D, Davey D, Kurman R, Moriarty A, O'Connor D, Prey M, Forum Group Members and Bethesda 2001 Workshop, et al: The 2001 Bethesda System: terminology for reporting results of cervical cytology. JAMA 2002, 287:2114-2119.

16. Carozzi F, Del Mistro A, Confortini M, Sani C, Puliti D, Trevisan R, et al: Reproducibility of HPV DNA testing by hybrid capture 2 in a screening setting: intralaboratory and interlaboratory quality control in seven laboratories participating in the same clinical trial. Am J Clin Pathol 2005, 124:1-6.

17. Castle PE, Schiffman M, Burk RD, Wacholder S, Hildesheim A, Herrero R, et al: Restricted cross-reactivity of hybrid capture 2 with nononcogenic human papillomavirus types. Cancer Epidemiol Biomarkers Prev 2002, 11:1394-1399.

18. Castle PE, Solomon D, Wheeler CM, Gravitt PE, Wacholder S, Shiffman M: Human Papillomavirus genotype specificity of Hybrid Capture 2. J Clin Microbiol 2008, 46:2595-2604

19. Bosch FX, Burchell AN, Schiffman M, Giuliano AR, de Sanjose S, Bruni L, et al: Epidemiology and natural history of human papillomavirus infections and type-specific implications in cervical neoplasia. Vaccine 2008, 26S:K1-K16.

20. Ripabelli G, Grasso GM, Del Riccio I, Tamburro M, Sammarco ML: Prevalence and genotype identification of human papilloma virus in women undergoing voluntary cervical cancer screening in Molise, central Italy. Cancer Epidemiology 2010, 34(2):162-167.

21. Masia G, Mazzoleni AP, Contu G, Laconi S, Minerba L, Montixi S, et al: Epidemiology and genotype distribution of human papillomavirus (HPV) in women of Sardinia (Italy). Vaccine 2009, 27:A11-A16.

22. Agarossi A, Ferrazzi E, Parazzini F, Perno CF, Ghisoni L: Prevalence and type distribution of high-risk human papillomavirus infection in women undergoing voluntary cervical cancer screening in Italy. J Med Virol 2009, 81:529-535.

23. Ronco G, Giubilato P, Naldoni C, Zorzi M, Anghinoni E, Scalisi A, et al: Extension of organised cervical cancer screening programmes in Italy and their process indicators, 2009 activity. Epidemiol Prev 2011, 35(Suppl. 5):39-54. 5-6.

24. De Sanjosè S, Diaz M, Castellsagué X, Clifford G, Bruni L, Muñoz N, et al: Worldwide prevalence and genotype distribution of cervical human papillomavirus DNA in women with normal cytology: a meta-analysis. Lancet Infect Dis 2007, 7:453-459.

25. De Francessco MA, Gargiulo F, Schreiber C, Ciravolo G, Salinaro F, Manca N: Detection and genotyping of human papillomavirus in cervical samples from Italian patients. J Med Virol 2005, 75:588-592.

26. Broccolo F, Chiari S, Piana A, Castiglia P, Dell'Anna T, Garcia-Parra R, et al: Prevalence and viral load of oncogenic human papilloma virus types associated with cervical carcinoma in a population of North Italy. J Med Virol 2009, 83:278-287.
27. Agodi A, Barchitta M, La Rosa N, Cipresso R, Guarnaccia M, Caruso M, et al: Human papillomavirus infection. Low-risk and high risk genotypes in women in Catania, Sicily. Int J Gynecol Cancer 2009, 19:1094-1098.

28. Piana A, Sotgiu G, Castiglia P, Pischedda S, Cocuzza C, Capobianco G, et al: Prevalence and type distribution of human papillomavirus infection in women from North Sardinia, Italy. BMC Publ Health 2011, 11:785.

29. Bouvard V, Baan R, Straif K, Grosse Y, Secretan B, El Ghissassi F, on behalf of the WHO International Agency for Research on Cancer Monograph Working Group, et al: Special report: policy. A review of human carcinogens-part B: biological agents. Lancet Oncol 2009, 10(4):321-322.

30. Ronco G, Segnan N, Giorgi-Rossi P, Zappa M, Casadei GP, Carozzi F, et al: Human papillomavirus testing and liquid-based cytology in primary cervical screening: results at recruitment from the New technologies for cervical cancer randomized controlled trial. J Natl Cancer Inst 2006, 98:765-774.

31. Ronco G, Giorgi-Rossi P, Carozzi F, Dalla Palma P, Del Mistro A, De Marco L, NTCC Working Group, et al: Human papillomavirus testing and liquidbased cytology in primary screening of women younger than 35 years: results at recruitment for a randomised controlled trial. Lancet Oncol 2006, 7:547-555

32. Giorgi-Rossi P, Chini F, Bisanzi S, Burroni E, Carillo G, Lattanzi A, The Prevalence Italian Working Group HPV, et al: Distribution of high and low risk HPV types by cytological status: a population based study from Italy. Infectious Agents and Cancer 2011, 6:2.

33. Shiffman M, Castle PE, Jeronimo J, Rodriguez AC, Wacholder S: Human paillomavirus and cervical cancer. Lancet 2007, 370:890-907.

34. Lenselink CH, Melchers WJ, Quint WG, Hoebers AM, Hendriks JC, Massuger LF, Bekkers RL: Sexual behaviour and HPV infections in 18 to 29 year old women in the pre-vaccine era in the Netherlands. PLoS One 2008, 3(11): e3743. Epub 2008 Nov 17.

35. Skjeldestad FE, Mehta $V$, Sings HL, Øvreness T, Turpin J, Su L, et al: Seroprevalence and genital DNA prevalence of HPV types 6, 11, 16 and 18 in a cohort of young Norwegian women: study design and cohort characteristics. Acta Obstet Gynecol Scand 2008, 87(1):81-88.

36. Martín P, Kilany L, García D, López-García AM, Martín-Azaña MJ, Abraira V, et al: Human papillomavirus genotype distribution in Madrid and correlation with cytological data. BMC Infect Dis 2011, 11:316.

37. Karlsson R, Jonsson M, Edlund K, Evander M, Gustavsson A, Bodén E, Rylander $E$, et al: Lifetime number of partners as the only independent risk factor for human papillomavirus infection: a population-based study. Sex Transm Dis 1995, 22(2):119-127.

38. Ronco G, Ghisetti V, Segnan N, Snijders PJ, Gillio-Tos A, Meijer CJ, et al: Prevalence of human papillomavirus infection in women in Turin, Italy. Eur J Cancer 2005, 41(2):297-305.

doi:10.1186/1471-2334-13-74

Cite this article as: Giambi et al:: A cross-sectional study to estimate high-risk human papillomavirus prevalence and type distribution in Italian women aged 18-26 years. BMC Infectious Diseases 2013 13:74.

\section{Submit your next manuscript to BioMed Central and take full advantage of:}

- Convenient online submission

- Thorough peer review

- No space constraints or color figure charges

- Immediate publication on acceptance

- Inclusion in PubMed, CAS, Scopus and Google Scholar

- Research which is freely available for redistribution 